\title{
Body Mass Index, Smoking, and Alcohol and Risks of Barrett's Esophagus and Esophageal Adenocarcinoma: A UK Prospective Cohort Study
}

\author{
Max Yates $\cdot$ Edward Cheong $\cdot$ Robert Luben . \\ Laszlo Igali $\cdot$ Rebecca Fitzgerald $\cdot$ Kay-Tee Khaw $\cdot$ \\ Andrew Hart
}

Received: 20 August 2013/Accepted: 30 December 2013/Published online: 6 February 2014

(C) The Author(s) 2014. This article is published with open access at Springerlink.com

\begin{abstract}
Background The timing of the risk factors cigarette smoking, alcohol and obesity in the development of Barrett's esophagus (BE) and esophageal adenocarcinoma (EAC) is unclear.

Aims To investigate these exposures in the aetiology of $\mathrm{BE}$ and EAC in the same population.

Methods The cohort included 24,068 men and women, aged 39-79 years, recruited between 1993 and 1997 into the prospective EPIC-Norfolk Study who provided information on anthropometry, smoking and alcohol intake. The cohort was monitored until December 2008 and incident cases identified.

Results One hundred and four participants were diagnosed with $\mathrm{BE}$ and 66 with EAC. A body mass index (BMI) above $23 \mathrm{~kg} / \mathrm{m}^{2}$ was associated with a greater risk of BE [BMI $\geq 23$ vs. 18.5 to $<23$, hazard ratio (HR) 3.73, $95 \%$ CI 1.37-10.16], and within a normal BMI, the risk was greater in the higher category (HR 3.76, $95 \%$ CI
\end{abstract}

M. Yates · E. Cheong $\cdot$ L. Igali $\cdot$ A. Hart $(\bowtie)$

Norfolk and Norwich University Hospital NHS Trust, Colney

Lane, Norwich NR4 7UY, UK

e-mail: a.hart@uea.ac.uk

M. Yates

e-mail: max.yates@nnuh.nhs.uk

E. Cheong

e-mail: Edward.Cheong@nnuh.nhs.uk

L. Igali

e-mail: Laszlo.Igali@nnuh.nhs.uk

R. Luben

Strangeways Research Laboratory, Worts Causeway,

Cambridge CB1 8RN, UK

e-mail: Robert.luben@phpc.cam.ac.uk
$1.30-10.85$, BMI $23-25$ vs. 18.5 to $>23 \mathrm{~kg} / \mathrm{m}^{2}$ ). Neither smoking nor alcohol intake were associated with risk for BE. For EAC, all BMI categories were associated with risk, although statistically significant for only the highest (BMI $>35$ vs. BMI 18.5 to $<23$, HR 4.95, $95 \%$ CI 1.11-22.17). The risk was greater in the higher category of a normal BMI (HR 2.73, $95 \%$ CI 0.93-8.00, $p=0.07$, BMI 23-25 vs. 18.5 to $>23 \mathrm{~kg} / \mathrm{m}^{2}$ ). There was an inverse association with $\geq 7$ units alcohol/week (HR 0.51, $95 \%$ CI 0.29-0.88) and with wine (HR 0.49, $95 \%$ CI $0.23-1.04, p=0.06$, drinkers vs. non-drinkers).

Conclusions Obesity may be involved early in carcinogenesis and the association with EAC and wine should be explored. The data have implications for aetiological investigations and prevention strategies.

Keywords Barrett's esophagus - Adenocarcinoma · Smoking $\cdot$ Alcohol $\cdot$ BMI 


\section{Introduction}

The incidence of esophageal adenocarcinoma (EAC) has increased by fivefold over the last three decades and is the sixth commonest cause of cancer death in the UK [1-3]. Barrett's esophagus (BE), the metaplastic change of the esophageal mucosa from squamous to a columnar type, is an established risk factor for EAC, with the rate of malignant change between 0.2 and $10 \%$ per year [4-7].

The plausible aetiological risk factors for BE and EAC include smoking, alcohol and obesity. The biological mechanisms include carcinogenic chemicals in cigarettes [8] and obesity, firstly accentuating reflux of both acid and bile into the lower esophagus, and secondly being a source of adipokines, which may be pathogenic [9]. Refluxed gastric juice may damage the esophageal mucosa, exposing the multi-potential stem cells in the basal layers to juice constituents that stimulate abnormal differentiation [10]. Although alcohol could have a corrosive effect, polyphenols present in wine have anti-oxidant properties and may reduce DNA damage.

The proposed experimental mechanisms for carcinogenesis need to be supported by population-based data. The strongest such information is from prospective cohort investigations, where risk factors are recorded prior to the development of symptoms. This approach minimises the recall bias for potential risk factors associated with casecontrol studies. For BE and body mass index (BMI), there are just two such cohort studies, one of which studied only women [11] reporting a positive association in obese participants. A second investigation found no effect in men, but a positive association in women [12]. For EAC, it is well documented that increasing obesity increases the risk of cancer [13-16]. Both diseases need to be studied in the same population to determine at which stage of carcinogenesis BMI may operate. In cohort studies, cigarette smoking doubles the risk of EAC [17, 18], whereas in the sparse work in BE, it is former, rather than current smoking, for which positive associations are reported [12, 19]. A pooled analysis of two cohort and ten case-control studies reported strong associations between cigarette smoking with both esophageal adenocarcinoma and junctional adenocarcinoma [20]. For alcohol, there are a limited number of prospective studies which report no associations for either BE or EAC [12, 17, 18] and no associations according to the specific intakes of either beer, wine or spirits.

The study's aims were to clarify whether smoking, BMI and alcohol are associated with the development of both $\mathrm{BE}$ and EAC. To the best of our knowledge, this would be the first time both have been simultaneously examined in the same population in a prospective study. BMI within the range 18.5 to $<25.0 \mathrm{~kg} / \mathrm{m}^{2}$ will be assessed to see if the risk varies across the conventional definition of a normal BMI. The World Health Organisation recommends a BMI of $23 \mathrm{~kg} / \mathrm{m}^{2}$ as a cut-point for public health actions [21]. The intakes of specific types of alcohol will be studied. Investigating these exposures will help clarify if they should be measured in future aetiological studies, which may have implications for cancer prevention.

\section{Methods}

We report results from 24,068 participants (54\% women) aged 39-74 years recruited into the European Prospective Investigation of Cancer-Norfolk (EPIC-Norfolk) study between 1993 and 1997, who were initially without diagnosed BE or EAC. Participants were registered in general practices in rural, suburban and inner city areas and completed questionnaires at baseline providing information on cigarette smoking and alcohol intake. Alcohol consumption was recorded in a food frequency questionnaire which listed different alcoholic beverages and the frequency of intake at recruitment, aged 20 years and aged 30 years. Participants attended baseline health checks at recruitment where their height and weight were measured by nurses, using standard protocols, from which their BMI was calculated $\left(\mathrm{kg} / \mathrm{m}^{2}\right)$.

Following recruitment, the cohort was monitored until December 2008 to identify incident cases of both BE (diagnosed at gastroscopy after referral predominantly for reflux symptoms) and EAC. This was achieved by matching subject identifiers on the histology database at the Norfolk and Norwich University Hospital (NNUH) with the EPIC database. Further cases of EAC were retrieved from the Eastern Region Cancer Registry. In total, $95 \%$ of the cohort received their clinical care for BE at the NNUH, and for EAC the figure is approximately $97.5 \%$. Twenty years after the cohort commenced recruitment, $94.6 \%$ of those still alive have local residential postcodes. The cohort was monitored until either the end of study date, date of death or loss to follow-up. The medical records of all identified participants were reviewed by two clinicians (MY and EC) to ascertain the dates of diagnosis, endoscopic appearances, and the length of the affected segment. For BE to be included, the gastroscopy report required the endoscopist to firstly document characteristic endoscopic appearances and, secondly, the pathologist to report columnar metaplasia of either intestinal, gastric or mosaic type. Cases were excluded that had either microscopic columnar metaplasia without endoscopic changes or no evidence of $\mathrm{BE}$ at a subsequent gastroscopy. Cases of gastric metaplasia were reviewed to ensure that macroscopic BE was seen above the esophagogastric junction. The medical notes and EPIC questionnaires were reviewed 
to ensure that there was no previous history of BE or EAC prior to enrolment into EPIC. Cases were excluded if BE was diagnosed within the first year after recruitment or 6 months for EAC. In this study, we could not detect asymptomatic Barrett's esophagus as the population was not screened endoscopically.

In the analysis, hazard ratios (HR) were estimated using Cox regression, for $\mathrm{BE}$ and EAC separately, adjusted for age at recruitment and gender. Cigarette smoking status was classified as "current," "never" or "former" smoking. Alcohol consumption was divided into the standard categories (units per week): none, $>0$ to $<7, \geq 7$ to $<14, \geq 14$ to $<21, \geq 21$ to $<28$ and $\geq 28$. BMI $\left(\mathrm{kg} / \mathrm{m}^{2}\right)$ was classed into 18.5 to $<23$ (lower normal), 23 to $<25$ (upper normal), $\geq 25$ to $<30$ (overweight), $\geq 30$ to $<35$ (obese) and $\geq 35$ (morbidly obese). Participants with a BMI of $<18.5 \mathrm{~kg} / \mathrm{m}^{2}$ were excluded as this value is defined as a below normal BMI and unrepresentative of the general population. A baseline category of BMI $18.5-23 \mathrm{~kg} / \mathrm{m}^{2}$ was chosen, rather than $<25 \mathrm{~kg} / \mathrm{m}^{2}$, to study the risk across the normal BMI range. A second analysis included smoking, alcohol intake and $\mathrm{BMI}$ in the same model.

\section{Results}

During follow-up, 284 potential cases of BE were identified from histopathological data, although after review of the medical notes, only 155 (55\%) were eligible. A total of $129(45 \%)$ participants were initially excluded ("Appendix"), the commonest reason being no evidence of endoscopically visible $\mathrm{BE}$ at the first gastroscopy after reviewing the case notes. A further 51 (18\%) were then excluded who had either a diagnosis for a previous cancer outside the esophagus (which could influence the representativeness of the exposures) or with incomplete baseline data. For the 104 confirmed cases of BE, the median age at diagnosis was 67.0 years (range 41.3-84.4 years, $79.8 \%$ men; Table 1), diagnosed after a median follow-up time of 6.2 years (range 1.1-13.3 years). The median length of $\mathrm{BE}$ at the initial diagnosis was $5 \mathrm{~cm}$ (range $1-10 \mathrm{~cm}$ ), with $93 \%$ having metaplasia, but no dysplasia. The metaplasia was classed as intestinal $70 \%$, gastric $9 \%$, mosaic $16 \%$ and not reported $5 \%$. In BE patients, $77 \%$ had reflux symptoms at the time of gastroscopy, with $73 \%$ having a hiatal hernia. The remaining $23 \%$ of patients were referred for investigation of iron deficiency anaemia. For EAC, there were 70 incident cases, of which four were excluded due to incomplete baseline health check data. Of the 66 cases, the median age at diagnosis was 73 years (range 52-86 years, $83.3 \%$ men; Table 2) with a median time between recruitment and diagnosis of 6.2 years (range 0.6-11.8 years). Information on the tumour site was available for $94 \%$ of patients, with $87 \%$ involving the gastro-esophageal junction. There were no cases with a BMI less than $18.5 \mathrm{~kg} / \mathrm{m}^{2}$, but 117 controls $(0.49 \%$ of the cohort). There was at least $97 \%$ completeness of data for all of the three risk factors in both conditions. The number of cases of both BE and EAC were similar to that estimated using information from two large UK databases [22, 23]. None of the EAC cases included had a prior history of screening or surveillance for BE. However, five of the incident BE cases did progress to EAC during follow-up. These were not included in the cancer analysis as they may have had life-style advice/interventions following the $\mathrm{BE}$ diagnosis which influenced their EAC risk.

Cases of BE were more likely than controls to be older, male, smokers and have greater BMIs (Table 1). In the multivariate analysis, there was a threshold association with all increasing categories of BMI at recruitment having a greater than threefold increased risk of BE (e.g. BMI $\geq 30$ to $<35$ vs 18.5 to $<23 \mathrm{~kg} / \mathrm{m}^{2}$, HR $3.22,95 \% \mathrm{CI}$ 1.04-10.02, $p=0.04$; Table 3). This effect persisted when a level of 18.5 to $<23 \mathrm{~kg} / \mathrm{m}^{2}$ was compared to a BMI of $\geq 23$ (HR 3.73, $95 \%$ CI 1.37-10.16). Similarly, in men, a BMI of $\geq 23 \mathrm{~kg} / \mathrm{m}^{2}$ was associated with an increased risk (HR 2.44, $95 \%$ CI 0.89-6.66, $p=0.08$ ), but there were insufficient numbers for this analysis in women. There were no statistically significant effects of smoking or alcohol at recruitment, respectively, on the risk of BE. The results were similar for each risk factor when the other two co-variants were included in the model. The attributable fraction for a $\mathrm{BMI} \geq 23 \mathrm{~kg} / \mathrm{m}^{2}$ was $70 \%$, i.e. the percentage of all cases with a BMI of this level. For alcohol intake, when participants were aged 20 and 30 years, no significant associations were seen in individual categories or for

Table 1 Characteristics of participants with and without confirmed Barrett's esophagus

\begin{tabular}{llll}
\hline Variable & $\begin{array}{l}\text { Cases } \\
(n=104)\end{array}$ & $\begin{array}{l}\text { Controls } \\
(n=23,876)\end{array}$ & $p$ value \\
\hline $\begin{array}{c}\text { Age at recruitment } \\
\text { (years, median, range) }\end{array}$ & $60.3(40.1-76.1)$ & $\begin{array}{l}58.7 \\
(39.5-77.1)\end{array}$ & $<0.01$ \\
$\begin{array}{c}\text { Age at diagnosis (years, } \\
\text { median, range) }\end{array}$ & $67.0(41.3-84.4)$ & - & $\mathrm{n} / \mathrm{a}$ \\
$\begin{array}{l}\text { Gender }(\% \text { male) } \\
\text { BMI }\left(\mathrm{kg} / \mathrm{m}^{2}, \text { median }\right.\end{array}$ & $79.8 \%$ & $46.1 \%$ & $<0.001$ \\
and range) & $26.8(21.1-39.4)$ & 25.9 & $<0.02$ \\
$\begin{array}{l}\text { Smoking } \\
\text { Never smoked }\end{array}$ & $13.5 \%$ & $(18.5-53.9)$ & \\
$\begin{array}{l}\text { Former smoker } \\
\text { Current smoker }\end{array}$ & $55.8 \%$ & $46.1 \%$ & 0.001 \\
$\begin{array}{l}\text { Alcohol consumption } \\
\text { (units per week, }\end{array}$ & $50.8 \%$ & $42.2 \%$ & 0.005 \\
median, range) & & $11.7 \%$ & 0.58 \\
\hline
\end{tabular}


Table 2 Characteristics of participants with and without confirmed esophageal adenocarcinoma (EAC)

\begin{tabular}{|c|c|c|c|}
\hline Variable & Cases $(n=66)$ & Controls $(n=24,000)$ & $p$ value \\
\hline Age at recruitment (years, median, range) & $67.0(46.7-76.3)$ & $58.8(39.5-79.1)$ & $<0.001$ \\
\hline Age at diagnosis (years, median, range) & $73(52-86)$ & - & \\
\hline Gender ( $\%$ male $)$ & $83.3 \%$ & $46.3 \%$ & $<0.001$ \\
\hline BMI $\left(\mathrm{kg} / \mathrm{m}^{2}\right.$, median and range $)$ & $26.5(20.1-42.8)$ & $25.9(18.5-53.9)$ & 0.24 \\
\hline \multicolumn{4}{|l|}{ Smoking } \\
\hline Never smoked & $27.7 \%$ & $46.0 \%$ & 0.003 \\
\hline Former smoker & $58.5 \%$ & $42.3 \%$ & 0.009 \\
\hline Current smoker & $13.8 \%$ & $11.7 \%$ & 0.59 \\
\hline Alcohol consumption (units per week, median and range) & $2.5(0.0-44.0)$ & $3.5(0-121)$ & 0.38 \\
\hline
\end{tabular}

the respective trends (HR 1.05, $95 \%$ CI $0.91-1.22$ \& HR $1.07,95 \%$ CI 0.92-1.23). Approximately half the cohort provided information on the type of alcohol consumed, and comparing non-drinkers to drinkers, no associations were seen for wine consumption (HR 0.90, $95 \%$ CI 0.48-1.69), beer (HR 1.55, $95 \%$ CI $0.73-3.29$ ) or spirits (HR 0.68, $95 \%$ CI $0.38-1.22)$.

Cases of EAC were more likely than controls to be older at recruitment, male and smokers (Table 2). All categories of BMI at recruitment were positively associated with an increased risk of EAC, although only the highest was statistically significant (BMI $\geq 35$ vs. BMI $<23 \mathrm{~kg} / \mathrm{m}^{2}$, HR 4.95, $95 \%$ CI 1.11-22.17, $p=0.04$; Table 4). There were no associations with smoking status, nor any individual category of alcohol intake at baseline, although there was an inverse trend with increasing categories of intake (HR $0.83,95 \%$ CI $0.67-1.03, p=0.09$ ). Alcohol intake of 7 units/week or more, compared to less, was inversely associated with risk (HR $0.51,95 \%$ CI $0.29-0.88$, $p=0.02$ ), with inverse associations in both sexes (men HR $0.54,95 \%$ CI $0.30-0.96$ \& women HR $0.31,95 \%$ CI 0.04-2.44). For alcohol intake at age 20 years and age 30 years, no significant associations were seen for categories or for the respective trends (HR trend $=1.04,95 \%$ CI $0.86-1.26$, HR trend $=1.02,95 \%$ CI $0.84-1.24)$. For the sub-types of alcohol, comparing non-drinkers to drinkers, an inverse association of borderline statistical significance, was detected for wine consumption (HR 0.49, $95 \%$ CI $0.23-1.04, p=0.06$ ), but not beer (HR 1.91, $95 \%$ CI $0.70-5.18$ ) or spirits (HR $0.68,95 \%$ CI $0.33-1.39)$. The magnitudes of all associations were similar when smoking, body mass index and alcohol were all included in the model. For BMI, the analysis was repeated excluding cases diagnosed less than a year within recruitment to exclude the possibility that subjects were already beginning to lose weight. This accentuated the results for all BMI categories, although only the highest was statistically significant (BMI $\geq 35$ vs. BMI $<23 \mathrm{~kg} / \mathrm{m}^{2}$, HR 6.65 , $95 \%$ CI $1.34-33.02, p=0.02$ ).
In a post hoc analysis, associations with waist/hip ratio (WHR) were investigated as WHR may be more representative of abdominal obesity than BMI [24, 25]. Here we categorised both genders, according to the gender specific definitions of WHR, into one of three grouped weight categories (normal, overweight \& obese) and calculated a trend across categories [24]. This showed a significant trend for both $\mathrm{BE}$ (RR trend $=1.35,95 \%$ CI 1.03-1.76, $p=0.03)$ and $\mathrm{EAC}(\mathrm{RR}$ trend $=1.43,95 \% \mathrm{CI} 1.03-2.00$, $p=0.03)$.

\section{Discussion}

A main finding of this study was that in each category of BMI greater than $23 \mathrm{~kg} / \mathrm{m}^{2}$, there was at least a tripling of the risk of BE, with higher BMIs associated with more than two-thirds of cases. For EAC, positive associations were seen in each category of BMI, although this was only statistically significant in the morbidly obese (BMI $\geq 35$ ). The conventional definition of a "normal" BMI is 18.5 to $<25.0 \mathrm{~kg} / \mathrm{m}^{2}$ and the increased risk suggested in the upper normal range, i.e. 23 to $<25 \mathrm{~kg} / \mathrm{m}^{2}$, in both BE and EAC is a concern, although the baseline BMI category in both included only four cases. This raises the issue of whether the definition of a "normal" BMI should be reconsidered. The rationale for including this range in the analysis is the WHO expert report [21] which recommended reporting disease risks in the category of $18.5-23 \mathrm{~kg} / \mathrm{m}^{2}$ for potential public health action. The reasons are unknown for the positive associations between BMI and both BE and EAC, suggested in a threshold level above $23 \mathrm{~kg} / \mathrm{m}^{2}$, rather than a dose-dependent manner with increasing BMI. Hypothetically, if carcinogenesis occurs through contact of constituents of the refluxate with the mucosa linked with BMI, this process may be initiated above a certain level of BMI and then other factors are involved in cancer progression. The findings from our work on BE are supported by other prospective cohorts $[11,12]$, although we have reported 
Table 3 Relationship between body mass index, alcohol intake and smoking status and the risk of developing Barrett's esophagus (BE)

\begin{tabular}{|c|c|c|c|c|}
\hline BMI $\left(\mathrm{kg} / \mathrm{m}^{2}\right)^{\mathrm{b}}$ & Cases $(n=104)$ & Controls $(n=23,829)$ & Hazard ratio $(95 \% \mathrm{CI})^{\mathrm{a}}$ & $p$ value \\
\hline 18.5 to $<23$ & 4 & 4,206 & 1.00 & - \\
\hline 23 to $<25$ & 24 & 5,113 & $3.76(1.30-10.85)$ & 0.01 \\
\hline 25 to $<30$ & 62 & 10,861 & $3.87(1.40-10.68)$ & $<0.01$ \\
\hline $30<35$ & 12 & 2,951 & $3.22(1.04-10.02)$ & 0.04 \\
\hline$\geq 35$ & 2 & 698 & $3.21(0.59-17.57)$ & 0.18 \\
\hline Alcohol (units per week) ${ }^{\mathrm{c}}$ & Cases $(n=103)$ & Controls $(n=23,633)$ & Hazard ratio $(95 \% \mathrm{CI})^{\mathrm{a}}$ & $p$ value \\
\hline No alcohol & 15 & 3,079 & 1.00 & - \\
\hline$>0$ to $<7$ & 39 & 12,091 & $0.61(0.33-1.11)$ & 0.10 \\
\hline 7 to $<14$ & 24 & 4,536 & $0.84(0.43-1.61)$ & 0.59 \\
\hline 14 to $<21$ & 9 & 2,005 & $0.64(0.28-1.49)$ & 0.30 \\
\hline 21 to $<28$ & 9 & 924 & $1.09(0.45-2.61)$ & 0.85 \\
\hline$>28$ units & 7 & 998 & $0.84(0.34-2.10)$ & 0.71 \\
\hline Smoking status $^{\mathrm{d}}$ & Case $(n=104)$ & Controls $(n=23,670)$ & Hazard ratio $(95 \% \mathrm{CI})^{\mathrm{a}}$ & $\overline{p \text { value }}$ \\
\hline Never smoked & 32 & 10,909 & 1.00 & - \\
\hline Former smoker & 58 & 9,995 & $1.38(0.88-2.16)$ & 0.16 \\
\hline Current smoker & 14 & 2,766 & $1.57(0.83-2.96)$ & 0.17 \\
\hline
\end{tabular}

${ }^{\text {a }}$ Adjusted for age and gender at recruitment

b Trend across categories of BMI HR $=1.20$ (95 \% CI 0.97-1.49, $p=0.09$ )

c Trend across categories HR $=1.04(0.90-1.21, p=0.60)$

${ }^{\mathrm{d}}$ Trend across categories HR $=1.28(0.95-1.72, p=0.11)$

this relationship in men with $\mathrm{BE}$ for the first time. In EAC, a US prospective investigation of 308,692 men and 211,702 women, documented a positive association with BMI, even in the normal range, as did our study in the UK [26]. In the former, the incremental increased risk of EAC per BMI unit was greater across the normal range than within the overweight and obese categories [26]. The rise in risk of EAC within the normal definition of BMI, now reported in two studies, would have implications for public health policy if the association is causal. There are several plausible biological mechanisms, in addition to attenuating reflux, for how an increased BMI may be involved in the development of BE and EAC. Visceral adipose tissue is metabolically active, increasing levels of interleukin-6, leptin, TNF-alpha and insulin-like growth factor-1, which may be involved in pathogenesis [9]. Leptin stimulates cell proliferation and inhibits apoptosis in Barrett's esophagusderived EAC cells which promotes the accumulation and persistence of genetic abnormalities [27]. In animal models, dietary animal fat increased the proportion of taurine conjugates in bile [28], which may damage cellular or mitochondrial membranes leading to proliferation.

This study found weak positive associations between smoking and $\mathrm{BE}$ or EAC, although these were not statistically significant. There were suggestions of positive trends in both conditions and larger numbers with longer follow-up are required to accrue more cases to provide clarification. Previous studies reported that smoking increased the risk of EAC [17, 18], although in BE it is former smoking which is important $[12,19]$. The reasons for this are uncertain, but a possibility is that those with $\mathrm{BE}$ had long-standing symptoms such as reflux before diagnosis which were exacerbated by cigarettes, and hence stopped smoking. For alcohol, we documented an inverse association for trend of borderline statistical significance $(p=0.09)$ between an increased intake and EAC. For participants drinking seven or more units per week, compared to those drinking less, there was a significant halving of the risk. This was due to alcohol from wine, rather than beer or spirits, which suggests any potential benefit is due to components in the wine, rather than the alcohol itself. No association was seen with $\mathrm{BE}$ which suggests any protective effect of wine may be in preventing the malignant transformation of metaplastic epithelium. The inverse association with wine and EAC may be explained by participants reducing their intake to ameliorate symptoms before diagnosis, although this is less likely as no such associations were seen for beer or spirits. Any benefit of alcohol may be due to that consumed in later life as no associations were 
Table 4 Relationship between body mass index, alcohol intake and smoking status and the risk of developing esophageal adenocarcinoma

\begin{tabular}{|c|c|c|c|c|}
\hline BMI $\left(\mathrm{kg} / \mathrm{m}^{2}\right)^{\mathrm{b}}$ & Cases $(n=65)$ & Controls $(n=23,906)$ & Hazard ratio $(95 \% \mathrm{CI})^{\mathrm{a}}$ & $\overline{p \text { value }}$ \\
\hline 18.5 to $<23$ & 4 & 4,216 & 1.00 & - \\
\hline 23 to $<25$ & 19 & 5,131 & $2.73(0.93-8.00)$ & 0.07 \\
\hline 25 to $<30$ & 32 & 10,932 & $1.82(0.64-5.17)$ & 0.26 \\
\hline 30 to $<35$ & 7 & 2,927 & $1.68(0.49-5.75)$ & 0.41 \\
\hline$\geq 35$ & 3 & 700 & $4.95(1.11-22.17)$ & 0.04 \\
\hline Alcohol (units per week) ${ }^{\mathrm{c}}$ & Cases $(n=66)$ & Controls $(n=23,755)$ & Hazard ratio $(95 \% \mathrm{CI})^{\mathrm{a}}$ & $p$ value \\
\hline No alcohol & 8 & 3,104 & 1.00 & - \\
\hline$>0$ to $<7$ & 40 & 12,135 & $1.34(0.63-2.88)$ & 0.45 \\
\hline 7 to $<14$ & 10 & 4,563 & $0.73(0.28-1.86)$ & 0.50 \\
\hline 14 to $<21$ & 3 & 2,015 & $0.47(0.12-1.79)$ & 0.27 \\
\hline 21 to $<28$ & 2 & 930 & $0.59(0.12-2.80)$ & 0.51 \\
\hline$>28$ & 3 & 1,008 & $0.83(0.22-3.18)$ & 0.79 \\
\hline Smoking status $^{\mathrm{d}}$ & Cases $(n=66)$ & Controls $(n=23,795)$ & Hazard ratio $(95 \% \mathrm{CI})^{\mathrm{a}}$ & $\overline{p \text { value }}$ \\
\hline Never smoked & 18 & 10,951 & 1.00 & - \\
\hline Former smoker & 39 & 10,063 & $1.27(0.71-2.27)$ & 0.41 \\
\hline Current smoker & 9 & 2,781 & $1.82(0.81-4.09)$ & 0.14 \\
\hline
\end{tabular}

${ }^{a}$ Adjusted for age and gender at recruitment

b Trend across categories HR $=1.10(0.83-1.44, p=0.51)$

c Trend across categories HR $=0.83(0.67-1.03, p=0.09)$

${ }^{\mathrm{d}}$ Trend across categories HR $=1.34(0.90-1.99, p=0.15)$

reported with that consumed at age 20 or 30 years. The BEACON Consortium, a pooled analysis of two cohort investigations and nine case-control studies, reported no overall effects of increasing intake of alcohol, although there were inverse associations with a moderate intake (0.5 to $<1$ drink/day) and EAC (OR $0.63,95 \%$ CI $0.41-0.99$ ), and junctional adenocarcinomas (OR 0.78, $95 \%$ CI 0.62-0.99) [29]. Previous prospective studies, which minimise recall biases, have not documented any associations with either $\mathrm{EAC}[17,18]$ or BE [12], including according to the specific intakes of beer, wine and spirits. However, the categories of alcohol intake analysed, and possibly the units of consumption, varied between these and our work, which may explain the discrepancies.

The strengths of this study were that there were minimal selection or recall biases, a methodological problem of case-control work. Furthermore, the Norfolk population is geographically stable so follow-up bias was reduced. All the cases were confirmed by reviewing the clinical notes for both endoscopic and histological criteria. There are limitations to our work, in that although all cancer cases will present, the BE cases were diagnosed as a result of symptoms. BE is also present in both asymptomatic individuals [30] and in those with reflux symptoms who do not seek medical help, two groups we could not identify or investigate. Additionally, not all symptomatic individuals had gastroscopy, as this will have been done according to individual need and referral practices. Whether the aetiology of both asymptomatic Barrett's esophagus and those not presenting or referred for investigation is different in patients diagnosed through investigation of reflux symptoms is unknown. A further limitation is that there may be residual confounding for BMI, including nutrients, and this work will progress to investigate diet. Only one measurement of risk factors was used, namely that at baseline and these may alter over time. However, such measurement error would result in an under-estimate of any true effect, rather than spurious over-estimates. Finally, the number of cases was relatively small, so the precision of the estimates was reduced and small associations may have gone undetected.

The increased risk within the upper limits of the normal range of BMI is a concern and suggests that the categories of BMI should perhaps be reconsidered. There was an inverse relationship between alcohol consumption of more than seven units per week and EAC, for which possible biological mechanisms need to be explored. To the best of our knowledge, this is the first study to report these three factors directly in both BE and EAC in the same population, which provides information on which 
stage of carcinogenesis they may act. Body mass index seems to be related to at least the development of $\mathrm{BE}$, and perhaps constituents of wine may prevent metaplastic progression to cancer. Our results support, firstly, measuring BMI in future aetiological studies including across the normal range of BMI and, secondly, according to the standardised intakes of alcohol. If the associations are causal, then reducing population BMI and giving recommendations on alcohol intake may help prevent a cancer which is increasing in incidence.

Acknowledgments EPIC-Norfolk is supported by the Medical Research Council UK (G1000143) and Cancer Research UK (C864/ A14136).

\section{Conflict of interest None.}

Open Access This article is distributed under the terms of the Creative Commons Attribution Noncommercial License which permits any noncommercial use, distribution, and reproduction in any medium, provided the original author(s) and the source are credited.

\section{Appendix}

See Table 5.

Table 5 Reasons for excluding identified participants with a potential diagnosis of Barrett's esophagus

\begin{tabular}{lll}
\hline Reason for exclusion & $\begin{array}{l}\text { Number } \\
(n=180)\end{array}$ & $\begin{array}{l}\text { Percentage } \\
\text { of all potential } \\
\text { cases }(284)\end{array}$ \\
\hline $\begin{array}{l}\text { No endoscopic evidence of BE at first } \\
\text { gastroscopy after review of notes }\end{array}$ & 35 & 12 \\
$\begin{array}{l}\text { No endoscopic evidence of BE at } \\
\text { follow-up gastroscopy }\end{array}$ & 30 & 11 \\
$\begin{array}{l}\text { Possible endoscopic appearances but } \\
\text { no confirmatory histology }\end{array}$ & 23 & 8 \\
$\begin{array}{l}\text { Histology at first diagnosis showed } \\
\text { esophageal cancer }\end{array}$ & 16 & 6 \\
$\begin{array}{l}\text { Search term error from original } \\
\text { histology data base search }\end{array}$ & 16 & 6 \\
$\begin{array}{l}\text { Notes unavailable to review } \\
\text { Previous esophageal surgery prior to } \\
\text { recruitment }\end{array}$ & 2 & 2 \\
$\begin{array}{l}\text { Participants reporting diagnosis and } \\
\text { treatment for a previous cancer } \\
\text { outside the oesophagus or with } \\
\text { incomplete baseline data }\end{array}$ & 51 & 18 \\
\hline
\end{tabular}

\section{References}

1. Cancer, Research, UK. CancerStats Oesophageal cancer-UK info.cancerresearchuk.org/cancerstats. 2005.
2. Corley DA, Buffler PA. Oesophageal and gastric cardia adenocarcinomas: analysis of regional variation using the cancer incidence in five continents database. Int J Epidemiol. 2001;30: $1415-1425$

3. Botterweck AA, Schouten LJ, Volovics A, Dorant E, van den Brandt PA. Trends in incidence of adenocarcinoma of the oesophagus and gastric cardia in ten European countries. Int $J$ Epidemiol. 2000;29:645-654.

4. Shaheen NJ, Richter JE. Barrett's oesophagus. Lancet. 2009;373: 850-861.

5. Bhat S, Coleman HG, Yousef F, et al. Risk of malignant progression in Barrett's Esophagus patients: results from a large population-based study. J Natl Cancer Inst. 2011;103(13): 1049-1057. doi:10.1093/jnci/djr203.

6. Desai TK, Krishnan K, Samala N, et al. The incidence of oesophageal adenocarcinoma in non-dysplastic Barrett's oesophagus: a meta-analysis. Gut. 2012;61(7):970-976. doi:10. 1136/gutjnl-2011-300730.

7. Hvid-Jensen F, Pedersen L, Drewes AM, Sørensen HT, FunchJensen P. Incidence of adenocarcinoma among patients with Barrett's Esophagus. N Engl J Med. 2011;365:1375-1383.

8. Hecht SS. Tobacco carcinogens, their biomarkers and tobaccoinduced cancer. Nat Rev Cancer. 2003;3:733-744.

9. Watanabe S, Hojo M, Nagahara A. Metabolic syndrome and gastrointestinal diseases. J Gastroenterol. 2007;42:267-274.

10. Seery JP. Stem cells of the oesophageal epithelium. J Cell Sci. 2002;115:1783-1789.

11. Jacobson BC, Chan AT, Giovannucci EL, Fuchs CS. Body mass index and Barrett's oesophagus in women. Gut. 2009;58: $1460-1466$

12. Steevens J, Schouten LJ, Driessen ALC, et al. A prospective cohort study on overweight, smoking, alcohol consumption, and risk of Barrett's Esophagus. Cancer Epidemiol Biomark Prev. 2011;20:345-358.

13. Steffen A, Schulze MB, Pischon T, et al. Anthropometry and Esophageal cancer risk in the European prospective investigation into cancer and nutrition. Cancer Epidemiol Biomark Prev. 2009; 18:2079-2089.

14. Corley DA, Kubo A, Zhao W. Abdominal obesity and the risk of Esophageal and gastric cardia carcinomas. Cancer Epidemiol Biomark Prev. 2008;17:352-358.

15. Merry AHH, Schouten LJ, Goldbohm RA, van den Brandt PA. Body mass index, height and risk of adenocarcinoma of the oesophagus and gastric cardia: a prospective cohort study. Gut. 2007;56:1503-1511.

16. Renehan AG, Tyson M, Egger M, Heller RF, Zwahlen M. Bodymass index and incidence of cancer: a systematic review and meta-analysis of prospective observational studies. Lancet. 2008;371:569-578.

17. Freedman ND, Abnet CC, Leitzmann MF, et al. A prospective study of tobacco, alcohol, and the risk of Esophageal and gastric cancer subtypes. Am J Epidemiol. 2007;165:1424-1433.

18. Steevens J, Schouten LJ, Goldbohm RA, van den Brandt PA. Alcohol consumption, cigarette smoking and risk of subtypes of oesophageal and gastric cancer: a prospective cohort study. Gut. 2010;59:39-48.

19. Jacobson B, Giovannucci E, Fuchs C. Smoking and Barrett's Esophagus in women who undergo upper endoscopy. Dig Dis Sci. 2011;56:1707-1717.

20. Cook MB, Kamangar F, Whiteman DC, et al. Cigarette smoking and adenocarcinomas of the Esophagus and Esophagogastric junction: a pooled analysis from the international BEACON consortium. J Natl Cancer Inst. 2010;102:1344-1353.

21. WHO, Expert, Consultation. Appropriate body-mass index for Asian populations and its implications for policy and intervention strategies The Lancet. 2004;363:157-163. 
22. Alexandropoulou K, van Vlymen J, Reid F, Poullis A, Kang JY. Temporal trends of Barrett's oesophagus and gastro-oesophageal reflux and related oesophageal cancer over a 10 -year period in England and Wales and associated proton pump inhibitor and H2RA prescriptions: a GPRD study. Eur J Gastroenterol Hepatol. $2013 ; 25: 15-21$.

23. Parkin DM, Ferlay J, Curado MP, et al. Fifty years of cancer incidence: CI5 I-IX. Int J Cance. 2010;127:2918-2927.

24. Dalton M, Cameron AJ, Zimmet PZ, et al. Waist circumference, waist-hip ratio and body mass index and their correlation with cardiovascular disease risk factors in Australian adults. $J$ Intern Med. 2003;254:555-563.

25. Lean MEJ, Han TS, Morrison CE. Waist circumference as a measure for indicating need for weight management. BMJ. 1995;311:158-161.

26. Abnet CC, Freedman ND, Hollenbeck AR, Fraumeni JF Jr, Leitzmann M, Schatzkin A. A prospective study of BMI and risk of oesophageal and gastric adenocarcinoma. Eur $J$ Cancer. 2008;44:465-471.
27. Ogunwobi O, Mutungi G, Beales IL. Leptin stimulates proliferation and inhibits apoptosis in Barrett's esophageal adenocarcinoma cells by cyclooxygenase-2-dependent, prostaglandin-E2mediated transactivation of the epidermal growth factor receptor and c-Jun NH2-terminal kinase activation. Endocrinology. 2006; 147:4505-4516.

28. Chen K-H, Mukaisho K-i, Sugihara H, Araki Y, Yamamoto G, Hattori T. High animal-fat intake changes the bile-acid composition of bile juice and enhances the development of Barrett's esophagus and esophageal adenocarcinoma in a rat duodenalcontents reflux model. Cancer Sci. 2007;98:1683-1688.

29. Freedman ND, Murray LJ, Kamangar F, et al. Alcohol intake and risk of oesophageal adenocarcinoma: a pooled analysis from the BEACON consortium. Gut. 2011;60:1029-1037.

30. Ward EM, Wolfsen HC, Achem SR, et al. Barrett's esophagus is common in older men and women undergoing screening colonoscopy regardless of reflux symptoms. Am $J$ Gastroenterol. 2006;101:12-17. 